\title{
Transarterial and transvenous access for neurointerventional surgery: report of the SNIS Standards and Guidelines Committee
}

\author{
Robert M Starke, ${ }^{1,2}$ Brian Snelling, ${ }^{1,2}$ Fawaz Al-Mufti, ${ }^{3}$ Chirag D Gandhi, ${ }^{2}$ \\ Seon-Kyu Lee, ${ }^{4}$ Guilherme Dabus, ${ }^{5}$ Justin F Fraser $\mathbb{1}^{\circ},{ }^{6}$ On Behalf of the Society of \\ Neurolnterventional Surgery
}

\begin{abstract}
${ }^{1}$ Neurological Surgery, University of Miami MILLER School of Medicine, Miami Beach, Florida, USA

${ }^{2}$ Neurosurgery, Westchester Medical Center, Valhalla, New York, USA

${ }^{3}$ Neurology and Neurosurgery, Westchester Medical Center,

Valhalla, New York, USA

${ }^{4}$ Radiology, Montefiore Hospital and Medical Center, Bronx, New York, USA

${ }^{5}$ Interventional Neuroradiology and Neuroendovascular

Surgery, Miami Cardiac and

Vascular Institute and Baptist

Neuroscience Center, Miami,

Florida, USA

${ }^{6}$ Neurological Surgery, University

of Kentucky, Lexington,

Kentucky, USA
\end{abstract}

\section{Correspondence to}

Dr Justin F Fraser, Neurological Surgery, University of Kentucky, Lexington, KY 40536, USA; Jfr235@uky.edu

RMS and BS contributed

equally.

Received 22 October 2019 Revised 7 November 2019 Accepted 12 November 2019 Published Online First

9 December 2019

\section{ABSTRACT}

The purpose of this publication is to provide a comprehensive review on the techniques and tools used for vascular access in neurointerventional procedures. Using published literature, we reviewed data on access methods, sites, tools, and techniques for neurointerventions. Recommendations are provided based on quality of data/levels of evidence and, where appropriate, expert consensus. While tools and techniques continue to be developed, current literature and experience supports certain principles regarding vascular access for neurointerventional procedures.

\section{INTRODUCTION}

The expansion of indications for neurointerventional procedures, combined with the need to treat a diverse patient population (including patients with tortuous anatomy and peripheral arterial disease), has driven a need for broader access options. ${ }^{1-4}$ There is literature supporting various techniques and tools for vascular access in patients undergoing neurointerventional radiology. However, vascular access is a fundamental requirement for any endovascular specialty, not solely neurointerventional radiology. This includes interventional cardiology and interventional radiology. Thus we aimed to develop recommendations based on the compendium of access literature, including that from neurointerventional and other interventional specialties, especially where the neurointerventional literature is lacking and other specialties have reported best practices or prospective randomized data.

\section{LITERATURE SEARCH}

The Standards and Guidelines Committee of the Society of NeuroInterventional Surgery (SNIS), a multidisciplinary society representing the leaders in the field of endovascular therapy for neurovascular disease, prepared this report from a comprehensive review of the currently available English language literature relating to the topic. A literature search using PubMed (US National Library of Medicine) and Ovid (Wolters Kluwer) databases was performed from 1980 to 2018, with these key words: transfemoral access, transradial access, transbrachial access, transcarotid access, direct carotid access, direct vertebral access, venous access, pediatric arterial access. References were also found through screening of review articles and textbook chapters.
Studies published in languages other than English were excluded. Recommendations follow the American College of Cardiology/American Heart Association classification of recommendation/level of evidence, and definition of classes and levels of evidence used in the American Heart Association/ American Stroke Association recommendations. ${ }^{5}$

\section{GENERAL CONSIDERATIONS}

There are several general principles of transarterial access that are broadly applicable to all access sites. First, data support the use of real time ultrasound guidance in arterial access, particularly in difficult access cases. In complex cases, it has been shown to reduce the number of attempts to successful cannulation, time to access, inadvertent vessel puncture, and access site complications in prospective randomized trials across multiple access sites and patient populations compared with arterial access based on fluoroscopic guidance, arterial palpation, or surface anatomical landmarks. ${ }^{6}$ The use of micropuncture access ( $21 \mathrm{~g}$ ) versus standard access (18 g) has been shown in a prospective trial of over 400 patients to reduce access site complications in patients without an elevated bleeding risk. ${ }^{7}$ Furthermore, increasing arterial sheath size is associated with an increase in access site complications across multiple access sites. ${ }^{8-10}$ Thus the smallest diameter sheath necessary to complete the procedure should be chosen. In addition, arteriography of the accessed artery should be performed to ensure adequacy of sheath placement. Post-procedure periodic assessment of the access site and neurovascular assessment of the involved extremity is recommended to facilitate the early detection of access site complications although no literature exists to guide the frequency or duration of this assessment.

\section{Recommendations}

- Ultrasound guidance should be considered for difficult access, and is reasonable for routine arterial access (unless surgical cut down (SCD) is to be used). (Class IIa, Level A)

- Micropuncture access may be reasonable to reduce access site complications compared with standard access techniques. (Class IIb, Level B)

- The use of the smallest diameter sheath possible to successfully perform angiography or neurointervention is recommended to minimize access site complications. (Class I, Level A) 
- Local contrast injection of the arterial access site should be performed prior to final access catheter placement to ensure appropriate sheath cannulation of the selected artery. (Class I, Level C-EO)

- Post-procedure periodic assessment of the access site and neurovascular assessment of the involved extremity is recommended to facilitate the early detection of access site complications. (Class I, Level C-EO)

\section{TRANSFEMORAL ARTERIAL ACCESS}

Transfemoral access (TFA) has traditionally been the preferred arterial access site for most neurointerventions and is used in $>95 \%$ of cases. ${ }^{11}$ TFA is the most common and best studied of the access sites in the neurointerventional literature.

Pre-procedure: severe atherosclerotic disease of the femoral vessels can both increase the difficulty of gaining TFA and increase the likelihood of ischemic access site complications. Alternative access sites may be considered in patients with known prior surgery, stenting, or occlusion of the femoral or iliac arteries or descending aorta.

Access technique: anatomical landmark based reference techniques theoretically reduce the risk of retroperitoneal hematoma. This approach prevents external iliac artery puncture above the inguinal ligament and facilitates hemostasis by allowing compression against the femoral head, as the common femoral artery has a consistent anatomical relationship to the femoral head. ${ }^{12}$ Fluoroscopic guidance for puncture over the femoral head has been shown in a prospective registry to reduce access site complications compared with anatomical landmark based puncture alone. However, three randomized trials failed to find any difference between the two groups other than a higher likelihood of ideal puncture location with fluoroscopy. ${ }^{13-15}$ Furthermore, in a prospective randomized trial, ultrasound guidance was shown to reduce the number of attempts, time to access, risk of inadvertent venipuncture, and risk of vascular complications compared with fluoroscopic guidance. ${ }^{16}$

Access site closure and post-procedure: vascular closure devices (VCDs) offer several theoretical benefits over manual compression in TFA: reduced time to hemostasis, reduced time to ambulation, reduced risk of access site complications, and increased patient comfort. However, significant heterogeneity exists in the literature comparing VCDs with manual compression as well as comparing different types of VCDs. A recent Cochrane Library review of this topic, assessing 52 randomized studies and more than 20000 patients, found no significant difference between VCDs and manual compression with regard to time to hemostasis and time to ambulation. Collagen based VCDs were shown to reduce the incidence of groin hematoma and pseudoaneurysm, but no other differences were seen for other types of VCDs (suture mediated or nitinol ring) or access site complications. Evidence supports common femoral artery angiography prior to placement of a VCD to prevent complications. ${ }^{17}$ Finally, length of bed rest following TFA reported in the literature varies widely, depending on sheath size, use of anticoagulation, risk factors for access site complications, and the use of VCDs versus manual compression. As such, no specific recommendation regarding length of bed rest can be made.

Complication avoidance and management: serious access site complications (including retroperitoneal hematoma, pseudoaneurysm, fistula, and dissection, among others) have been reported in $1.4-11.65 \%$ of neurointerventional procedures. ${ }^{18-20}$ Complications can present with pain, bruising, or swelling of the access site, flank or back pain diminished distal pulses, decrease in hemoglobin or, in severe cases, hemodynamic instability from hypovolemic shock (even resulting in death). Diagnosis of retroperitoneal hematoma can be made clinically as well as confirmed by CT scan or femoral arteriography, and can be treated with transfusion, endovascular repair of the bleeding site, or possible surgical evacuation. Pseudoaneurysm can present with groin swelling or pain, diagnosed with ultrasound, and can be managed conservatively, with compression or thrombin injection, or surgical treatment. Femoral artery occlusion usually presents with diminished or absent pulses, parasthesias, and weakness of the leg. The diagnosis is made clinically and via Doppler ultrasound, and generally treated with anticoagulation or surgery.

\section{Recommendations}

- Alternative access sites to TFA may be considered in patients with known prior surgery, stenting, or occlusion of the femoral or iliac arteries or descending aorta. (Class IIb, Level $C-E O)$

- Fluoroscopic guidance can be beneficial to reduce access site complications and ensure access over the inferior femoral head compared with anatomic landmark based access alone. (Class IIa, Level B)

- The effectiveness of VCDs in reducing time to hemostasis compared with manual compression is uncertain. (Class IIb, Level C-LD)

- The effectiveness of VCDs in reducing time to ambulation compared with manual compression is uncertain. (Class IIb, Level C-LD)

- The use of collagen based VCDs may be considered to reduce access site complications, specifically groin hematoma and pseudoaneurysm. (Class IIb, Level C-LD)

\section{TRANSRADIAL ARTERIAL ACCESS}

Transradial access (TRA) is the best studied alternative access site in neurointervention. Multiple large retrospective single center series have demonstrated the safety and efficacy of transradial cerebral angiography. ${ }^{21-27}$ In addition, complex interventions for both ischemic and hemorrhagic disease of the posterior and anterior circulation have been reported, highlighting the feasibility of this approach despite the use of femoral designed devices. ${ }^{11}{ }^{28-35}$ Furthermore, the best practices of TRA and closure have been extensively studied in the cardiology literature, as the reduction in access site complications from TRA has driven conversion worldwide among cardiologists. ${ }^{36}$ Despite these findings, TRA is currently utilized in $<5 \%$ of neurointerventional procedures although the conversion to TRA has been much discussed recently in both social media and society meetings. ${ }^{11}$ Although TRA site complication rates compare similarly between retrospective neurovascular studies and the cardiology literature, there is currently insufficient information comparing TRA with TFA with regards to other extracranial and intracranial complications.

Pre-procedure: traditionally, assessment of the collateral circulation to the hand via Allen's test and the Barbeau (using pulse oximetry and plethysmography) test has been utilized prior to TRA. However, significant controversy exists regarding the need for pre-procedural collateral circulation testing. ${ }^{3738}$ These tests have not provided adequate prediction of post-procedure hand ischemia in studies of utilization, supporting the presence of a dynamic collateral circulation of the hand and wrist regardless of the pre-procedure testing results. ${ }^{39}$ However, given the potentially devastating complication of hand ischemia and the theoretical role of collateral circulation testing in reducing the chance of this complication, its use has not been abandoned despite the inability of the Allen's or Barbeau test to predict complications. 


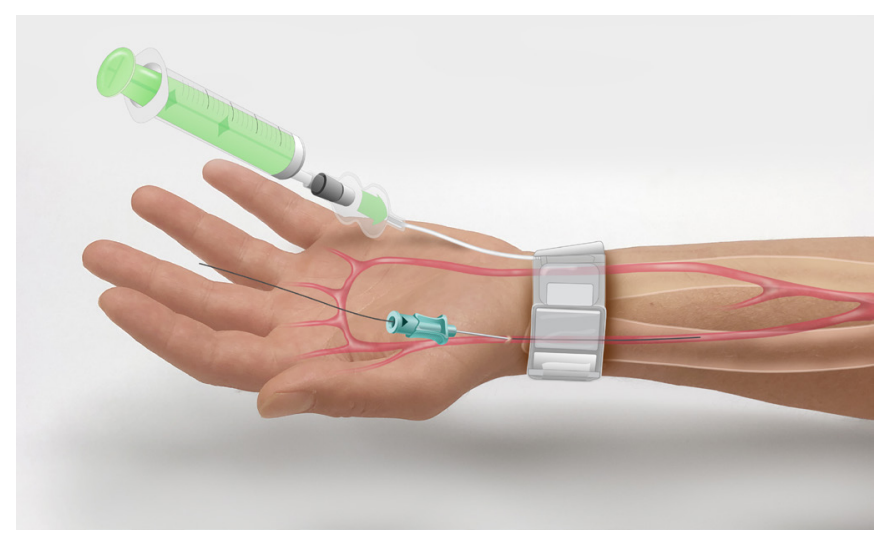

Figure 1 Access of the radial artery with a micropuncture needle and wire, along with a wrist band for patent hemostasis technique closure.

Of note, the MATRIX trial randomized more than 4000 patients to TRA (regardless of the pre-procedure collateral testing result) and found $0 \%$ incidence of post-procedure symptomatic hand ischemia. ${ }^{40}$ Symptomatic hand ischemia following TRA remains a 'case reportable' phenomenon. Administration of topical lidocaine and nitroglycerin at least $30 \mathrm{~min}$ prior to puncture has been shown prospectively to increase the diameter of the radial artery and facilitate TRA. ${ }^{41}$ In addition, subcutaneously administered nitroglycerin has similarly shown benefit in facilitating TRA. ${ }^{42} 43$

Access site technique: the use of the counterpuncture technique, as opposed to puncture of the anterior wall only, has been shown prospectively to reduce the number of attempts to achieve access, and thus time to achieve access. ${ }^{44} 45$ Radial access is traditionally obtained $2-3 \mathrm{~cm}$ proximal to the palmar wrist crease. Recent series have reported both cerebral angiography and neurointerventions successfully performed via access more distally in the anatomical snuffbox, obviating the need for wrist supination, allowing for re-access at the more proximal site, and providing operator comfort during left radial access. ${ }^{46} 47$ Administration of unfractionated heparin at therapeutic levels $(50 \mathrm{U} /$ $\mathrm{kg}$ or $5000 \mathrm{U}$ ) has been shown prospectively to lead to a sixfold reduction in radial artery occlusion (RAO) rates, with higher rates of administration $(100 \mathrm{U} / \mathrm{kg}$ ) further decreasing RAO incidence. ${ }^{48-50}$ Furthermore, the best route for heparin administration remains unclear, with no difference between intravenous or intra-arterial bolus administration through a sheath with regard to RAO rates. ${ }^{48} 51$ The administration of intra-arterial antispasmodic medications has been shown prospectively in multiple trials to reduce radial artery spasm (RAS) although without a clear consensus on the most effective combination and dose. ${ }^{52-54}$ A meta-analysis of 22 randomized trials found the lowest rates of RAS following intra-arterial administration of nitroglycerin $200 \mu \mathrm{g}$ and verapamil $5 \mathrm{mg}$. ${ }^{55}$ The choice of sheath size plays an important role in TRA, given its smaller diameter compared with other arterial access sites. Prospective studies have demonstrated a difference between what size sheath the radial artery can accommodate versus what size will result in the greatest post-procedure patency rates. While essentially clinically silent, prevention of RAO is important, especially with regard to consideration of further procedures. RAO rates have been shown to increase with increasing sheath diameter, especially when the outer diameter of the sheath exceeds the inner diameter of the radial artery. The use of sheathless TRA has been described and allows for larger inner diameter guide catheters to be placed without an attendant increase in outer diameter from sheath placement. $^{56}$

Access site closure: radial artery patency rates are significantly affected by the method of radial artery closure-namely, utilization of a patent hemostasis technique (figure 1). The use of patent hemostasis has been shown prospectively to reduce rates of RAO by $75 \%$ compared with conventional pressure application, either manually or with a compressive hemostatic band. ${ }^{21}$ Furthermore, prophylactic ulnar artery compression, when combined with patent hemostasis and other standard practices, results in $\mathrm{RAO}$ rates $<1 \% .^{57}$

Post-procedure: although use of patent hemostasis is paramount to preventing RAO, there is no consensus on the optimal protocol for deflation of the radial hemostatic band. ${ }^{58}$

Complication avoidance and management: the two most common complications associated with TRA are RAS and RAO. RAS can occur in up to $15-30 \%$ of patients, which can be reduced to $6-10 \%$ following intra-arterial administration of nitroglycerin and a calcium channel blocker. ${ }^{59}$ Recalcitrant RAS can be managed with further administration of antispasmodic medications. RAO occurs in $<1 \%$ of cases with modern prevention techniques, including heparin administration and patent hemostasis, as highlighted above. Furthermore, RAO is clinically silent in the majority of cases secondary to collateral circulation via the palmar arch. If RAO is encountered immediately postoperatively, ulnar compression can promote recanalization. ${ }^{60}$ If RAO persists, administration of low molecular weight heparin can increase patency. ${ }^{60}$

\section{Recommendations}

- Pre-procedural collateral circulation testing, including Allen's and Barbeau tests, is not useful in predicting ischemic complications associated with TRA and should not be used for access site triage. (Class III, Level A)

- The counterpuncture technique can be effective in the reduction of time to radial artery access and number of attempts needed to access compared with the anterior puncture technique. (Level IIa, Class B)

- Anticoagulation, in the form of unfractionated heparin at a dose of $50 \mu \mathrm{g} / \mathrm{kg}$ or $5000 \mathrm{U}$, should be administered to reduce the risk of $R A O$. (Class I, Level A)

- Patent hemostasis (figure 1), including prophylactic ipsilateral ulnar artery compression, should be used to reduce the risk of RAO. (Class I, Level A)

- Use of sheaths with an outer diameter smaller than the inner diameter of the radial artery is recommended to reduce the risk of RAO. (Class I, Level B-NR)

- The intra-arterial administration of antispasmolytic agents, including verapamil and nitroglycerin, can be useful in the prevention of RAS. (Class IIa, Level B-R)

- Assessment of radial artery patency prior to discharge and at the first postoperative visit is recommended to mitigate the risk of RAO. (Class I, Level C-EO)

\section{TRANSBRACHIAL ARTERIAL ACCESS}

Transbrachial arterial access (TBA) for both angiography and interventions has been described in the neurointerventional literature when TFA cannot be performed safely for reasons such as small radial artery/sheath size ratio or due to aortic arch or supra-aortic vessel tortuosity. ${ }^{61-65}$ The larger diameter compared with the radial artery offers the advantage of placement of larger guiding catheters and devices at a cost of an increased chance of limb ischemia due to less robust collateral circulation and increased access site complications due to its deeper location 
within the tissues of the brachium. Its current role in neurointervention is relegated to an alternative access site, and as such is used in a small minority of procedures.

As a cautionary note, atherosclerotic disease at the site of puncture on ultrasound can complicate access.

Access site technique: no current prospective trials exist regarding the optimal technique for TBA. Use of SCD has also been described for TBA, especially in cases requiring anticoagulation or in sheath sizes of $7 \mathrm{~F}$ or greater. ${ }^{66}$ Sheath sizes up to $9 \mathrm{~F}$ have been reported via the brachial artery, again with the use of SCD to mitigate complications. ${ }^{67}$

Access site closure: manual compression is the most commonly accepted and reported method. Various VCDs have been reported. ${ }^{68-70}$ The largest series, a retrospective analysis of the Angio-Seal device (St Jude Medical, St Paul, Minnesota, USA), reported major and minor complication rates of $3.1 \%$ and $7.5 \%$, respectively. ${ }^{71}$ Of note, small brachial artery diameter and atherosclerotic plaque have been described as contraindications to placement of a closure device. The literature does not favor closure devices over manual compression, and the reported complications between SCD and closure appear to be similar. ${ }^{67}$

Post-procedure: due to a paucity of clinical literature, no specific recommendation regarding the length of compression and immobilization can be made.

Complication avoidance and management: major complications (brachial artery occlusion resulting in limb ischemia, pseudoaneurysm or hematoma requiring surgery or transfusion, nerve palsy) have been prospectively reported in $2.3-5.5 \%$ of TBA endovascular interventions, with minor complications occurring in up to $14 \% .^{67} 71-74$ Complication avoidance lies in appropriate patient selection, with SCD and closure in the setting of large sheath diameters and anticoagulation. While certain complications can be managed conservatively, nearly two-thirds of major TBA complications require surgical management. Thus early vascular surgery consultation is recommended in the setting of any potential complication.

Currently, there is inadequate literature to guide TBA approaches. As complication rates appear higher than femoral, TFA, or TRA, this site should only be considered as an alternative when these options are not possible.

\section{Recommendations}

- TBA is not recommended as a primary access site. (Class III, Level C-LD)

- TBA may be considered as an alternative access site when other arterial access sites have failed or are not feasible. (Class IIb, Level C-LD).

\section{DIRECT CAROTID AND VERTEBRAL ARTERIAL ACCESS}

Direct carotid arterial or vertebral access (DCVA) is not recommended for routine angiography. DCVA may be used as an alternative site for access when other safer access points are not possible, and the clinical situation requires diagnostic information that cannot be achieved in any other way, or to perform therapeutic interventions that must be accomplished. This site may be used for emergency stroke thrombectomy or treatment of vascular pathology when anatomy precludes other access avenues. Due to the limited area within the carotid sheath, arterial bleeding can result in major complications. Its current role in neurointervention is relegated to a last resort alternative access site in urgent or emergent circumstances.

Pre-procedure: patients with known stenosis or occlusion of the distal common, internal carotid, or vertebral arteries should not receive DCVA. Intubation should be considered for DCVA to ensure protection of the airway intra- and post-procedurally. ${ }^{7576}$

Access site technique: no current prospective trials exist regarding the optimal technique for DCVA. Real time sonographic guidance and angiography with or without roadmap assistance may decrease complication rates. Single wall arterial puncture is important to reduce complications, and the use of SCD has also been described. The sheath should be secured in place with sutures. Given the low volume of studies on this method, no clear comparisons of sheath/shuttle length or size are available. There are no trials regarding the optimal closure methods in DCVA. Manual compression is a commonly accepted and reported method of arterial closure. In patients with large sheaths and anticoagulation, direct surgical repair is another option. This option allows for opening of the carotid sheath which holds the carotid artery, internal jugular artery, and vagus nerve. This would also allow placement of a subcutaneous drain that can decrease bleeding complications after primary repair especially in patient receiving anticoagulation, antiplatelets, or post-tissue plaminogen activator. The use of various VCDs has been reported. Currently, there is inadequate literature to guide optimal closure in these patients. ${ }^{75-77}$

Post-procedure: post-procedure, consideration should be made to keep patients intubated for airway protection. There is insufficient evidence to guide length of immobilization after arteriotomy closure but consideration of type of closure, concomitant anticoagulation, and sheath size should be undertaken.

Complication avoidance and management: major access site complications include carotid artery stenosis, occlusion, or bleeding. Bleeding from the access site can be particularly grave given the proximity to the trachea. This can result in rapid airway compromise making reintubation difficult or impossible. Complication avoidance lies in appropriate patient selection and meticulous access and closure. Due to the potential for significant complications, this access site is only used when other avenues are not possible and neurointervention is critical.

\section{TRANSVENOUS ACCESS}

Transvenous access (TVA) has diagnostic and therapeutic utility in neuroendovascular surgery, ranging from diagnostic venography and venous sampling to transvenous embolization, thrombectomy, and stenting. TVA is considered the route of choice for the treatment of a wide range of neuroendovascular conditions that include, but are not limited to, inferior petrosal sinus sampling, mechanical thrombectomy in cerebral venous sinus thrombosis, venous stenting for idiopathic intracranial hypertension, and embolization of vein of Galen malformations, dural arteriovenous fistula, and carotid-cavernous fistula. ${ }^{78-87}$

Pre-procedure: in patients with known thrombosis involving the common femoral vein, the contralateral side should be selected. While access is most frequently obtained using landmarks, routine ultrasound assistance may allow for evaluation of underlying thrombosis and a reduction in access site complications. TVA via the brachial, internal jugular, and superior ophthalmic vein should be accessed with ultrasound due to the proximity to the brachial plexus, the common carotid artery, and the globe, respectively. Most neuroendovascular procedures requiring TVA are conducted under general anesthesia, and systemic anticoagulation is administered. ${ }^{88} 89$

Access site technique: prospective trials regarding the optimal technique for TVA are lacking. For femoral venous access, the puncture site is typically $1 \mathrm{~cm}$ medial to the femoral pulse, just below the inguinal ligament. Spontaneous blood return from the $18-21 \mathrm{~g}$ needle may not necessarily be obtained but aspiration of 


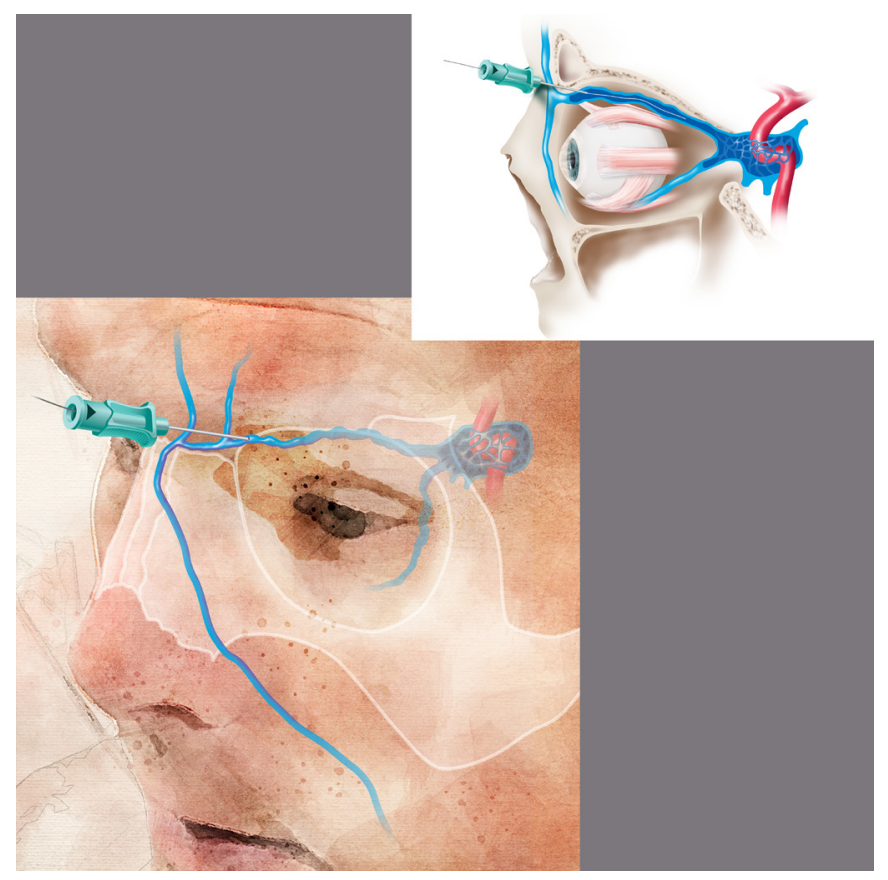

Figure 2 Direct superficial cannulation of the superior ophthalmic vein with micropuncture and microwire. This location has the benefit that it is superficial and bleeding can be easily controlled. Puncture of the superior ophthalmic vein distal to the superior orbital fissure or the cavernous sinus has the benefit that the vein is held in place by bony anatomy and is less mobile. Bleeding following access of these sites is more challenging to control.

blood with a syringe should confirm venous access. Fluoroscopic visualization of the wire to the right of the spine confirms intravenous access. Next, under direct fluoroscopic visualization, an appropriate guidewire is inserted to facilitate sheath or catheter placement. A 4 or $5 \mathrm{~F}$ sheath is typically appropriate for diagnostic procedures while a 6 or $7 \mathrm{~F}$ sheath is preferred for neuroendovascular interventions. For TVA to the cavernous sinus, direct internal jugular puncture provides an alternative access point. Ultrasound guidance is recommended. If endovascular access to the internal jugular vein is not possible due to tortuosity, septations, diverticuli, or the presence of thrombus, access can often be obtained via direct puncture or venous cut down of the superior ophthalmic, facial, or angular vein (figure 2 ). In the case of direct puncture, if the vein is not superficial, angiography with or without roadmap assistance can help guide needle placement. In the case of cut down, a small incision is made in the skin crease above the upper eyelid and the arterialized venous branch is identified and tracked proximally to identify the main trunk of the arterialized superior ophthalmic vein. ${ }^{78} 82858890$ This should be performed by a trained ophthalmologist or neurosurgeon. Cannulation of the facial or angular vein may provide an alternative approach along with direct puncture of the cavernous sinus as an alternative means of access when the above options are not possible. ${ }^{91}{ }^{92}$ There is inadequate literature to support one approach over the others, but the least invasive option is optimal.

Post-procedure: Due to the low pressures, manual compression of TVA for $5-10 \mathrm{~min}$ is an accepted closure technique in the absence of an untreated fistula (which would cause elevated, pulsatile pressure). Although not common practice, venous hemostasis with a closure device may be considered when access site hemostasis is challenging due to anticoagulation or coagulopathies. Alternatively, the patient can be kept immobilized and the sheath left in place until activated clotting time is $<150$ and then removal may be performed with manual compression. ${ }^{88}$ A brief period of bed rest following TVA may be considered, especially in the setting of anticoagulation. ${ }^{88}$

Complication avoidance and management: no cases of iatrogenic arteriovenous fistula formation have been reported from transarterial access and TVA at the same access site but it remains a theoretical possibility. TVA can be associated with the development of acute cerebral venous sinus thrombosis and hence anticoagulation is recommended, especially with prolonged interventions. Furthermore, deep vein thrombosis, as well as pulmonary emboli, may occur. ${ }^{86}$ Venous perforation may result in intracranial bleeding and although less common than in arterial interventions, groin complications can occur with TVA. ${ }^{88}$

\section{Recommendations}

- Ultrasound guidance may be used to mitigate TVA site complications. (Class IIb, Level C-EO)

- TVA should be performed with anticoagulation to minimize the risks of venous thromboembolism and thromboembolic complications. (Class I, Level C-LD)

- Manual compression of venous access points is safe, appropriate, and reasonable. (Class IIb, Level C-EO)

\section{PEDIATRIC ACCESS}

Pediatric arterial catheterization is technically challenging, mainly due to the small diameter of the access artery and associated underlying morbidities, such as prematurity. Pediatric femoral catheterization has been reported as having higher access site complication risks (up to 40\%) compared with those in adults. ${ }^{93-97}$ Acute or short term complications include puncture site vasospasm, acute loss of arterial pulse (LOP), and arterial dissection. Long term complications include ipsilateral limb length retardation and capital femoral necrosis. ${ }^{93-97}$ However, adopting ultrasound guided arterial puncture technique, systemic anticoagulation, and careful selection of catheter size have significantly reduced the femoral puncture site complication risks $(<5 \%))^{97-99}$ Umbilical artery access and carotid puncture have also been reported with reasonably low complication risks in limited circumstances. ${ }^{87} 100$

Pre-procedure: manual palpation and, if possible, ultrasound examination of bilateral femoral arteries are recommended to access adequate arterial flow and localization of the puncture site. As a common femoral artery (CFA) diameter of $<3 \mathrm{~mm}$ was found to be an independent predictor of LOP, CFA access avoidance in such vessels should be considered. ${ }^{97}$ In the case of umbilical access for neonates, either an existing umbilical arterial catheter or a patent umbilical artery needs to be verified.

Access site technique: the standard arterial access site for most pediatric patients is the CFA. Alternative access sites, including axillary, brachial, and umbilical arteries, can be chosen in certain circumstances. Also, direct access to carotid and vertebral arteries may be necessary in selected cases. ${ }^{101}$ The ultrasound guided CFA puncture technique and the low angle puncture technique are recommended as these have shown significantly reduced puncture site complications. ${ }^{97} 102$ Although there is no prospective controlled study available, considering the potential benefits of minimal arterial injury, use of the anterior wall puncture with micropuncture technique seems to be desirable as it minimizes trauma to the vessel. Selection of appropriate arterial sheath size is another critical step to reduce access site complications. In general, a trans-umbilical approach is favored in patients $<3 \mathrm{~kg}$ whose 
umbilical artery is accessible, a $4 \mathrm{~F}$ sheath can be used for children weighing 3-10 kg, and up to $5 \mathrm{~F}$ arterial sheath for children weighing 10-15 kg. ${ }^{99}$ Using the measured CFA diameter for the selection of arterial sheath size can be complex. The mean diameter of the CFA in patients $<1$ year old and $\geq 1$ year old was $3.2+/-1.1 \mathrm{~mm}$ and $5.4+/-0.8 \mathrm{~mm}$, respectively. ${ }^{97}$ The extrapolated estimated diameter of the CFA at 5 years old and 12 years old based on both angiographic and ultrasound measurements, were approximately $6 \mathrm{~mm}$ and about $7 \mathrm{~mm}$, respectively. ${ }^{103} 104$ The outer diameter of the currently available $4 \mathrm{~F}, 5 \mathrm{~F}$, and $6 \mathrm{~F}$ arterial sheaths are $1.8,2.3$, and $2.6 \mathrm{~mm}$, respectively. Therefore, if the CFA diameter is $>3 \mathrm{~mm}$ and for a child $<1$ year old, a $4 \mathrm{~F}$ arterial sheath should be assumed as a safe size. In children aged between 1 and 5 years old, up to a $5 \mathrm{~F}$ sheath appears to be a safe choice. After 6 years of age, up to a $6 \mathrm{~F}$ arterial sheath can be used based on prior reports. However, it would always be desirable to use ultrasound to measure the puncture site CFA diameter before finalizing the size of the arterial sheath. Known potential risk factors for CFA spasm and LOP include (1) absolute diameter of the CFA $<3 \mathrm{~mm}$, (2) the mean artery/catheter outer diameter ratio of $<50 \%$, and (3) $<1.9 \mathrm{~mm}$ difference between CFA diameter and outer diameter of the catheter. ${ }^{95} 105$

In the case of umbilical artery access, it is desirable to use an umbilical arterial catheter (Radio-opaque 3.5 F, Argyle, Tyco Healthcare Group, Mansfield, Massachusetts, USA) to select and establish umbilical access. Then, introduce either a 0.025 or 0.035 inch wire, through the umbilical catheter and exchange it with a $4 \mathrm{~F}$ arterial sheath (figure 1). The tip of the arterial sheath can be located at the iliac artery or within the aorta. In the case of a short staged neurointerventional procedure, the $4 \mathrm{~F}$ arterial sheath can remain with continuous perfusion with either heparinized saline or heparinized dextrose.

For access site closure, manual compression is recommended. Puncture site closure device applications such as Angioseal (St Jude Medical) and MynxGrip (Cordis) have been reported off-label in selected patients (CFA diameter $>4 \mathrm{~mm}$ ). However, such devices are approved by the Food and Drug Administration only for patients aged 18 years and over. ${ }^{106} 107$ Use of closure devices may potentially decrease immobilization time, decrease the length of hospital stay, and possibly reduce the risk of rebleeding, considering the low compliance of the pediatric cohort. ${ }^{106}$ However, its use must be carefully tailored considering the risk benefit ratio in each pediatric patient, particularly when considering the off-label nature of use.

Post-procedure: bed rest is recommended following femoral access, with the length depending on the use of anticoagulation, size of the sheath, and use of VCDs, but typically ranges between 2 and 6 hours. Neurological and pulse checks are done routinely during the postoperative period.

Complication avoidance and management: use of prepuncture ultrasound examination, selection of the least invasive access site (eg, in the neonate, umbilical artery access may be less traumatic than CFA access), appropriate arterial sheath size selection, and systemic anticoagulation must be carefully considered to prevent potential complications. Systemic anticoagulation after femoral artery access generally uses unfractionated heparin $(100 \mathrm{IU} / \mathrm{kg})$. The benefits of continuous flush through the arterial sheath with heparinized saline during the case in the pediatric cohort has not been clearly studied. However, considering its significant role in adults, the technique is likely preventive for access site arterial LOP. On the other hand, care should be taken to prevent potential volume overload during the interventional procedure.
Despite all preventive measures and even in very experienced operators, puncture site LOP is still a well known complication in pediatric catheterizations. Systemic fibrinolytic therapy, surgical thrombectomy, and endovascular thrombolysis have all be reported and resulted in reasonably good outcomes. ${ }^{108-113}$ However, considering young age, the small size of the pediatric femoral artery, frequent association of arterial spasm and comorbidities, conservative management, including anticoagulation and systemic fibrinolytic therapy, is recommended although these also have some risks in this patient population. ${ }^{114}$ The most commonly used protocol for conservative management of post-catheterization femoral LOP is continuing for at least $12-48$ hours anticoagulation using intravenous unfractionated heparin. If limb ischemia persists, consider systemic fibrinolytic therapy using $0.5 \mathrm{mg} / \mathrm{kg} /$ hour for about 6 hours. In the case of contraindications for conservative management, for persistent limb ischemia even after therapeutic anticoagulation or imminent limb ischemia, either surgical or endovascular management should be considered.

\section{Recommendations}

- Selection of sheath size based on patient age and CFA diameter on ultrasound is reasonable to prevent access site complications. (Class IIa, Level B-NR)

\section{SUMMARY OF RECOMMENDATIONS \\ General considerations}

- Ultrasound guidance should be considered for difficult access, and is reasonable for routine arterial access (unless SCD is to be used). (Class IIa, Level A)

- Micropuncture access may be reasonable to reduce access site complications compared with standard access techniques. (Class IIb, Level B)

- The use of the smallest diameter sheath possible to successfully perform angiography or neurointervention is recommended to minimize access site complications. (Class I, Level A)

- Local contrast injection of the arterial access site should be performed prior to final access catheter placement to ensure appropriate sheath cannulation of the selected artery. (Class I, Level C-EO)

- Post-procedure periodic assessment of the access site and neurovascular assessment of the involved extremity is recommended to facilitate the early detection of access site complications. (Class I, Level C-EO)

\section{Transfemoral arterial access}

- Alternative access sites to TFA may be considered in patients with known prior surgery, stenting, or occlusion of the femoral or iliac arteries or descending aorta. (Class IIb, Level C- EO)

- Fluoroscopic guidance can be beneficial to reduce access site complications and ensure access over the inferior femoral head compared with anatomic landmark based access alone. (Class IIa, Level B)

- The effectiveness of vascular closure devices in reducing time to hemostasis when compared with manual compression is uncertain. (Class IIb, Level C-LD)

- The effectiveness of VCDs in reducing time to ambulation compared with manual compression is uncertain. (Class IIb, Level C-LD)

- The use of collagen based VCDs may be considered to reduce access site complications, specifically groin hematoma and pseudoaneurysm. (Class IIb, Level C-LD) 


\section{Transradial arterial access}

- Pre-procedural collateral circulation testing, including Allen's and Barbeau tests, is not useful in predicting ischemic complications associated with TRA and should not be used for access site triage. (Class III, Level A)

- The counterpuncture technique can be effective in the reduction of time to radial artery access and number of attempts needed to access compared with the anterior puncture technique. (Level IIa, Class B)

- Anticoagulation, in the form of unfractionated heparin at a dose of $50 \mu \mathrm{g} / \mathrm{kg}$ or $5000 \mathrm{U}$, should be administered to reduce the risk of RAO. (Class I, Level A)

- Patent hemostasis (figure 1), including prophylactic ipsilateral ulnar artery compression, should be used to reduce the risk of RAO. (Class I, Level A)

- Use of sheaths with an outer diameter smaller than the inner diameter of the radial artery is recommended to reduce the risk of RAO. (Class I, Level B-NR)

- The intra-arterial administration of antispasmolytic agents, including verapamil and nitroglycerin, can be useful in the prevention of RAS. (Class IIa, Level B-R)

- Assessment of radial artery patency prior to discharge and at the first postoperative visit is recommended to mitigate the risk of RAO. (Class I, Level C-EO)

\section{Transbrachial arterial access}

- TBA is not recommended as a primary access site. (Class III, Level C-LD)

- TBA may be considered as an alternative access site when other arterial access sites have failed or are not feasible. (Class IIb, Level C-LD)

\section{Transvenous access}

- Ultrasound guidance may be used to mitigate TVA site complications. (Class IIb, Level C-EO)

- TVA should be performed with anticoagulation to minimize the risks of venous thromboembolism and thromboembolic complications. (Class I, Level C-LD)

- Manual compression of venous access points is reasonable (Class IIb, Level C-EO)

\section{Pediatric access}

- Selection of sheath size based on patient age and CFA diameter on ultrasound is reasonable to prevent access site complications. (Class IIa, Level B-NR)

\section{Twitter Robert M Starke @Starke_neurosurgery}

Acknowledgements We appreciate the work of Tom Dolan in providing the medical illustrations for this publication.

Collaborators On Behalf of the Society of Neurolnterventional Surgery: SA Ansari, AS Arthur, M Bain, B Baxter, KR Bulsara, M Chen, R De Leacy, K Fargen, D Frei, S Hetts, MS Hussain, MV Jayaraman, P Kan, Y Kayan, RP Klucznik, WJ Mack, T LeslieMazwi, RA McTaggart, JM Milburn, PM Meyers, M Mokin, J Mocco, AT Patsalides, CJ Prestigiacomo, GL Pride Jr, AS Puri, AT Rai, C Schirmer, AH Siddiqui and G Toth.

Contributors RMS, BS, FAM, CDG, and S-KL were the primary authors and, as such, were responsible for overseeing construction of the document outline, gathering of evidence, and drafting of the manuscript. GD acted as a representative of the Board of the Society of Neurolnterventional Surgery, and provided commentary and editing on behalf of the Board and of the Society as a whole. JFF, as senior author, was responsible for organizing the writing group, overseeing the outline construction, facilitating communication between the writing group and the Standards and Guidelines Committee, drafting and editing of the manuscript, and the submission/proofing for publication.

Funding This research received no specific grant from any funding agency in the public, commercial, or not-for-profit sectors. It is funded solely from internal resources of the Society of Neurolnterventional Surgery.

Disclaimer This literature review ("Review") is provided for informational and educational purposes only. Adherence to any recommendations included in this Review will not ensure successful treatment in every situation. Furthermore, the recommendations contained in this Review should not be interpreted as setting a standard of care, or be deemed inclusive of all proper methods of care nor exclusive of other methods of care reasonably directed to obtaining the same results. The ultimate judgment regarding the propriety of any specific therapy must be made by the physician and the patient in light of all the circumstances presented by the individual patient, and the known variability and biological behavior of the medical condition. This Review and its conclusions and recommendations reflect the best available information at the time the Review was prepared. The results of future studies may require revisions to the recommendations in this Review to reflect new data. SNIS does not warrant the accuracy or completeness of the Review and assumes no responsibility for any injury or damage to persons or property arising out of or related to any use of this Review or for any errors or omissions.

Competing interests JFF is an equity interest holder for Cerelux, and for Fawkes Biotechnology, LLC, and a consultant for Stream Biomedical, Penumbra, and Medtronic Neurovascular. He has research support from the University of Kentucky and the American Heart Association. RMS receives research support from NREF, Joe Niekro Foundation, Brain Aneurysm Foundation, Bee Foundation, NIH, Miami Clinical and Translational Science Institute, National Center for Advancing Translational Sciences and the National Institute on Minority Health and Health Disparities. He is a consultant for Penumbra, Abbott, Medtronic, and Cerenovus. GD is a consultant for Medtronic, Microvention, Penumbra, and Cerenovus. He is a shareholder in InNeuroCo, RIST, Cleerly, and eLum. BS has equity in RIST Neurovascular. Dr Kan is a consultant for Stryker and Medtronic Neurovascular. YK is a consultant for Penumbra and for Medtronic Neurovascular. PMM is a consultant for Stryker, Medtronic, Penumbra, and Siemens. ASA is a consultant for Balt, Johnson and Johnson, Leica, Medtronic, Microvention, Penumbra, Scientia, Siemens, and Stryker. He has research support from Cerenovus, Microvention, Penumbra and Siemens. He is a shareholder in Bendit, Cerebrotech, Endostream, Magneto, Marblehead, Neurogami, Serenity, Synchron, Triad Medical, and Vascular Simulations. BB is a consultant for Penumbra, Medtronic, Stryker, Metactive, and 880 Medical, He has stock in Penumbra, and stock options in Viz.ai. He has ownership interest in Route 92 and Marblehead. MC is a consultant for Medtronic, Stryker, Genentech, Imperative Health, Microvention, and Cerenovus. RDL is a consultant for Imperative Care, Siemens, and Penumbra, and owns equity in Q'Apel. He is also on the scientific advisory boards for Cerenovus and receives research support from Asahi and Medtronic. KF is a consultant for Cerebrotech. DF is a consultant for Genentech, Penumbra, and Stryker. He has stock ownership in Penumbra. SH has a Royalty Agreement with Penumbra. He Contracts for Core Imaging Lab for Stryker and MicroVention. He has a research contract with Siemens. He is on Data Safety and Monitoring Boards for DAWN, ARISE2, and PHIL trials. He has grant support through $\mathrm{NCl}$ and NIBIB. MSH is a consultant for Cerenovus. MVJ is a speaker for Medtronic. RPK is a consultant for Medtronic, Cerenovus, and Microvention. WJM is a consultant for Q'Apel, Rebound Therapeutics, Viseon TSP, Medtronic, Penumbra, and Stream Biomedical. He is an investor in Cerebrotech, Endostream, Viseon, and Rebound Therapeutics.JMM is a consultant for Stryker and Penumbra. MM is a consultant for Canon Medical and Medtronic. He has financial interest in Serenity Medical and VICIS. JM receives research support from Stryker, Penumbra, Medtronic, and Microvention. He is a consultant for Imperative Care, Cerebrotech, Viseon, Endostream, Rebound Therapeutics, and Vastrax. He is an investor/shareholder in BlinkTBI, Serenity, NTI, Neurvana, and Cardinal Consulting. GLP is a consultant for Sequent and Microvention-Terumo. He is on the Data Safety and Monitoring Board for Web-IT Study (Cerenovus) and for the Pulserider NAPA trial. ATR is a consultant for Stryker Neurovascular and Microventions. He is on an Advisory Board for Cerenovus, and is a stockholder in NTI. CS has equity in Neurotechnology Investors. AHS receives research support from NIH. He has financial interests in Amnis Therapeutics, BlinkTBI, Buffalo Technology Partners, Cardinal Consultants, Cerebrotech Medical Systems, Cognition Medical, Endostream Medical, Imperative Care, International Medical Distribution Partners, Neurovascular Diagnostics, Q'Apel Medical, Rebound Therapeutics, Rist Neurovascular, Serenity Medical, Silk Road Medical, Spinnaker Medical, StimMed, Synchron, Three Rivers Medical, and Viseon Spine. He is a consultant for Amnis Therapeutics, Boston Scientific, Canon Medical Systems, Cerebrotech Medical Systems, Cerenovus, Corindus, Endostream Medical, Guidepoint Global Consulting, Imperative Care, Integra, Medtronic, MicroVention, Northwest University, Penumbra, Q'Apel Medical, Silk Road Medical, StimMed, Stryker, Three Rivers Medical, VasSol, and WL Gore and Associates. Dr Toth is a consultant for Dynamed EBSCO.

Patient consent for publication Not required.

Provenance and peer review Not commissioned; externally peer reviewed.

Data availability statement There are no independent data in this work.

ORCID iD

Justin F Fraser http://orcid.org/0000-0002-5980-3989 


\section{REFERENCES}

1 Berkhemer OA, Fransen PSS, Beumer D, et al. A randomized trial of intraarterial treatment for acute ischemic stroke. N Engl J Med 2015;372:11-20.

2 Brott TG, Hobson RW, Howard G, et al. Stenting versus endarterectomy for treatment of carotid-artery stenosis. N Engl J Med 2010;363:11-23.

3 Nogueira RG, Jadhav AP, Haussen DC, et al. Thrombectomy 6 to 24 hours after stroke with a mismatch between deficit and infarct. N Engl J Med 2018;378:11-21.

4 Spetzler RF, McDougall CG, Zabramski JM, et al. The Barrow Ruptured Aneurysm Trial: 6-year results. J Neurosurg 2015;123:609-17.

5 Morrison LJ, Gent LM, Lang E, et al. Part 2: evidence evaluation and management of conflicts of interest: 2015 American Heart Association guidelines update for cardiopulmonary resuscitation and emergency cardiovascular care. Circulation 2015; 132:\$368-82

6 Marquis-Gravel G, Tremblay-Gravel M, Lévesque J, et al. Ultrasound guidance versus anatomical landmark approach for femoral artery access in coronary angiography: a randomized controlled trial and a meta-analysis. J Interv Cardiol 2018;31:496-503.

7 Ambrose JA, Lardizabal J, Mouanoutoua $M$, et al. Femoral micropuncture or routine introducer study (femoris). Cardiology 2014;129:39-43.

8 Doyle BJ, Ting HH, Bell MR, et al. Major femoral bleeding complications after percutaneous coronary intervention: incidence, predictors, and impact on long-term survival among 17,901 patients treated at the Mayo Clinic from 1994 to 2005. JACC Cardiovasc Interv 2008;1:202-9.

9 Metz D, Meyer P, Touati C, et al. Comparison of $6 \mathrm{~F}$ with $7 \mathrm{~F}$ and $8 \mathrm{~F}$ guiding catheters for elective coronary angioplasty: results of a prospective, multicenter, randomized trial. Am Heart J 1997;134:131-7.

10 Sherev DA, Shaw RE, Brent BN. Angiographic predictors of femoral access site complications: implication for planned percutaneous coronary intervention. Catheter Cardiovasc Interv 2005;65:196-202.

11 Haussen DC, Nogueira RG, DeSousa KG, et al. Transradial access in acute ischemic stroke intervention. J Neurointerv Surg 2016:8:247-50.

12 Garrett PD, Eckart RE, Bauch TD, et al. Fluoroscopic localization of the femoral head as a landmark for common femoral artery cannulation. Catheter Cardiovasc Interv 2005;65:205-7.

13 Jacobi JA, Schussler JM, Johnson KB. Routine femoral head fluoroscopy to reduce complications in coronary catheterization. Proc (Bayl Univ Med Cent) 2009;22:7-8.

14 Fitts J, Ver Lee P, Hofmaster P, et al. Fluoroscopy-guided femoral artery puncture reduces the risk of $\mathrm{PCl}$-related vascular complications. J Interv Cardiol 2008;21:273-8.

15 Abu-Fadel MS, Sparling JM, Zacharias SJ, et al. Fluoroscopy vs. traditional guided femoral arterial access and the use of closure devices: a randomized controlled trial. Catheter Cardiovasc Interv 2009;74:533-9.

16 Seto AH, Abu-Fadel MS, Sparling JM, et al. Real-time ultrasound guidance facilitates femoral arterial access and reduces vascular complications: FAUST (femoral arterial access with ultrasound trial). JACC Cardiovasc Interv 2010;3:751-8.

17 Patel MR, Jneid H, Derdeyn CP, et al. Arteriotomy closure devices for cardiovascular procedures: a scientific statement from the American Heart Association. Circulation 2010;122:1882-93

18 Jovin TG, Chamorro A, Cobo E, et al. Thrombectomy within 8 hours after symptom onset in ischemic stroke. N Engl J Med 2015;372:2296-306.

19 Goyal M, Demchuk AM, Menon BK, et al. Randomized assessment of rapid endovascular treatment of ischemic stroke. N Engl J Med 2015;372:1019-30.

20 Campbell BCV, Mitchell PJ, Kleinig TJ, et al. Endovascular therapy for ischemic stroke with perfusion-imaging selection. N Eng/ J Med 2015:372:1009-18.

21 Snelling BM, Sur S, Shah SS, et al. Transradial cerebral angiography: techniques and outcomes. J Neurointerv Surg 2018;10:874-81.

22 Park J-H, Kim D-Y, Kim J-W, et al. Efficacy of transradial cerebral angiography in the elderly. J Korean Neurosurg Soc 2013;53:213-7.

23 Nohara AM, Kallmes DF. Transradial cerebral angiography: technique and outcomes. AJNR Am J Neuroradiol 2003;24:1247-50.

24 Nagayoshi K, Ikeda M, Hirai N, et al. [Usefulness of selective cerebral angiography by transradial approach]. Nihon Igaku Hoshasen Gakkai Zasshi 2000;60:28-32.

25 Matsumoto Y, Hongo K, Toriyama T, et al. Transradial approach for diagnostic selective cerebral angiography: results of a consecutive series of 166 cases. AJNR Am J Neuroradiol 2001;22:704-8.

26 Levy El, Boulos AS, Fessler RD, et al. Transradial cerebral angiography: an alternative route. Neurosurgery 2002;51:335-42.

27 Jo KW, Park SM, Kim SD, et al. Is transradial cerebral angiography feasible and safe? A single center's experience. J Korean Neurosurg Soc 2010:47:332-7.

28 Sur S, Snelling B, Khandelwal P, et al. Transradial approach for mechanical thrombectomy in anterior circulation large-vessel occlusion. Neurosurg Focus 2017;42:E13.

29 Schönholz C, Nanda A, Rodríguez J, et al. Transradial approach to coil embolization of an intracranial aneurysm. J Endovasc Ther 2004;11:411-3.

30 Ruzsa Z, Nemes B, Pintér L, et al. A randomised comparison of transradial and transfemoral approach for carotid artery stenting: RADCAR (radial access for carotid artery stenting) study. Eurolntervention 2014;10:381-91.
31 Peitz GW, Kura B, Johnson JN, et al. Transradial approach for deployment of a flow diverter for an intracranial aneurysm in a patient with a type-3 aortic arch. J Vasc Interv Neurol 2017;9:42-4.

32 Mendiz OA, Sampaolesi AH, Londero HF, et al. Initial experience with transradial access for carotid artery stenting. Vasc Endovascular Surg 2011;45:499-503.

33 Goland J, Doroszuk G, Garbugino S, et al. Transradial approach to treating endovascular cerebral aneurysms: case series and technical note. Surg Neurol Int 2017:8:73.

34 Dietrich C, Hauck GH, Valvassori L, et al. Transradial access or Simmons shaped $8 \mathrm{~F}$ guide enables delivery of flow diverters in patients with large intracranial aneurysms and type III aortic arch: technical case report. Neurosurgery 2013;73:onsE111-5.

35 Daou B, Chalouhi N, Tjoumakaris S, et al. Alternative access for endovascular treatment of cerebrovascular diseases. Clin Neurol Neurosurg 2016;145:89-95.

36 Snelling BM, Sur S, Shah SS, et al. Transradial access: lessons learned from cardiology. J Neurointerv Surg 2018;10:487-92.

37 Valgimigli M, Campo G, Penzo C, et al. Transradial coronary catheterization and intervention across the whole spectrum of Allen test results. J Am Coll Cardiol 2014:63:1833-41.

38 Barbeau GR, Arsenault F, Dugas L, et al. Evaluation of the ulnopalmar arterial arches with pulse oximetry and plethysmography: comparison with the Allen's test in 1010 patients. Am Heart J 2004;147:489-93.

39 Bertrand OF, Carey PC, Gilchrist IC. Allen or no Allen: that is the question! J Am Coll Cardiol 2014:63:1842-4.

40 Valgimigli M, Frigoli E, Leonardi S, et al. Radial versus femoral access and bivalirudin versus unfractionated heparin in invasively managed patients with acute coronary syndrome (matrix): final 1-year results of a multicentre, randomised controlled trial. Lancet 2018;392:835-48.

41 Beyer AT, Ng R, Singh A, et al. Topical nitroglycerin and lidocaine to dilate the radial artery prior to transradial cardiac catheterization: a randomized, placebo-controlled, double-blind clinical trial. Int J Cardiol 2013;168:2575-8.

42 Ezhumalai B, Satheesh S, Jayaraman B. Effects of subcutaneously infiltrated nitroglycerin on diameter, palpability, ease-of-puncture and pre-cannulation spasm of radial artery during transradial coronary angiography. Indian Heart J 2014:66:593-7.

43 Candemir B, Kumbasar D, Turhan S, et al. Facilitation of radial artery cannulation by periradial subcutaneous administration of nitroglycerin. J Vasc Interv Radiol 2009;20:1151-6.

44 Seto AH, Roberts JS, Abu-Fadel MS, et al. Real-time ultrasound guidance facilitates transradial access: RAUST (radial artery access with ultrasound trial). JACC Cardiovasc Interv 2015:8:283-91.

45 Pancholy SB, Sanghvi KA, Patel TM. Radial artery access technique evaluation trial: randomized comparison of Seldinger versus modified Seldinger technique for arterial access for transradial catheterization. Catheter Cardiovasc Interv 2012;80:288-91.

$46 \mathrm{McC}$ arthy DJ, Chen SH, Brunet M-C, et al. Distal radial artery access in the anatomical snuffbox for neurointerventions: case report. World Neurosurg 2019;122:355-9

47 Brunet M-C, Chen SH, Sur S, et al. Distal transradial access in the anatomical snuffbox for diagnostic cerebral angiography. J Neurointerv Surg 2019;11:710-3.

48 Spaulding C, Lefèvre T, Funck F, et al. Left radial approach for coronary angiography: results of a prospective study. Cathet Cardiovasc Diagn 1996;39:365-70.

49 Dahal K, Sharma S, Yousuf A, et al. A comparison of standard versus low dose heparin on access-related complications after coronary angiography through radial access: a meta-analysis of randomized controlled trials. Cardiovasc Revasc Med 2018:19:575-9.

50 Hahalis GN, Leopoulou M, Tsigkas G, et al. Multicenter randomized evaluation of high versus standard heparin dose on incident radial arterial occlusion after transradial coronary angiography: the spirit of ARTEMIS study. JACC CardiovasC Interv 2018;11:2241-50.

51 Pancholy SB. Comparison of the effect of intra-arterial versus intravenous heparin on radial artery occlusion after transradial catheterization. Am J Cardiol 2009;104:1083-5.

52 Rosencher J, Chaïb A, Barbou F, et al. How to limit radial artery spasm during percutaneous coronary interventions: the spasmolytic agents to avoid spasm during transradial percutaneous coronary interventions (SPASM3) study. Catheter Cardiovasc Interv 2014:84:766-71.

53 Kiemeneij F, Vajifdar BU, Eccleshall SC, et al. Evaluation of a spasmolytic cocktail to prevent radial artery spasm during coronary procedures. Catheter Cardiovasc Interv 2003; $58: 281-4$

54 Chen C-W, Lin C-L, Lin T-K, et al. A simple and effective regimen for prevention of radial artery spasm during coronary catheterization. Cardiology 2006;105:43-7.

55 Kwok CS, Rashid M, Fraser D, et al. Intra-arterial vasodilators to prevent radial artery spasm: a systematic review and pooled analysis of clinical studies. Cardiovasc Revasc Med 2015:16:484-90

56 Horie K, Tada N, Isawa T, et al. A randomised comparison of incidence of radial artery occlusion and symptomatic radial artery spasm associated with elective transradial coronary intervention using 6.5 Fr SheathLess Eaucath guiding catheter vs. $6.0 \mathrm{Fr}$ Glidesheath slender. Eurolntervention 2018;13:2018-25. 
57 Pancholy SB, Bernat I, Bertrand OF, et al. Prevention of radial artery occlusion after transradial catheterization: the PROPHET-II randomized trial. JACC Cardiovasc Interv 2016;9:1992-9.

58 Dangoisse V, Guédès A, Chenu P, et al. Usefulness of a gentle and short hemostasis using the transradial band device after transradial access for percutaneous coronary angiography and interventions to reduce the radial artery occlusion rate (from the prospective and randomized CRASOC I, II, and III studies). Am J Cardiol 2017;120:374-9.

59 Caputo RP, Tremmel JA, Rao S, et al. Transradial arterial access for coronary and peripheral procedures: Executive summary by the Transradial Committee of the Scal. Catheter Cardiovasc Interv 2011;78:823-39.

60 Bernat I, Bertrand OF, Rokyta R, et al. Efficacy and safety of transient ulnar artery compression to recanalize acute radial artery occlusion after transradial catheterization. Am J Cardiol 2011;107:1698-701.

61 Zaidat 00, Szeder V, Alexander MJ. Transbrachial stent-assisted coil embolization of right posterior inferior cerebellar artery aneurysm: technical case report. J Neuroimaging 2007;17:344-7.

62 Okawa M, Tateshima S, Liebeskind D, et al. Successful recanalization for acute ischemic stroke via the transbrachial approach. J Neurointerv Surg 2016:8:122-5.

63 Kawajiri K, Matsuoka Y, Hayazaki K, et al. [Utility of selective cerebral angiography through the transbrachial route]. No Shinkei Geka 1994;22:235-9.

64 Iwata T, Mori T, Tajiri H, et al. Initial experience of a novel sheath guide for transbrachial coil embolization of cerebral aneurysms in the anterior cerebral circulation. Neurosurgery 2013:72:15-19.

65 Horton TG, Kalapos P, Cockroft KM. Brachial artery approach for endovascular treatment of posterior circulation intracranial vascular disease: technique and application in 5 cases. J Stroke Cerebrovasc Dis 2012;21:68-74.

66 Dorfer C, Standhardt H, Gruber A, et al. Direct percutaneous puncture approach versus surgical cutdown technique for intracranial neuroendovascular procedures: technical aspects. World Neurosurg 2012;77:192-200.

67 Alvarez-Tostado JA, Moise MA, Bena JF, et al. The brachial artery: a critical access for endovascular procedures. J Vasc Surg 2009;49:378-85.

68 Puggioni A, Boesmans E, Deloose K, et al. Use of starclose for brachial artery closure after percutaneous endovascular interventions. Vascular 2008;16:85-90

69 Hertting K, Raut W. Successful use of the mynxgrip closure device during repeated transbrachial percutaneous peripheral intervention. Case Rep Vasc Med 2015:2015:1-4.

70 Belenky A, Aranovich D, Greif F, et al. Use of a collagen-based device for closure of low brachial artery punctures. Cardiovasc Intervent Radiol 2007:30:273-5.

71 Lupattelli T, Clerissi J, Clerici G, et al. The efficacy and safety of closure of brachial access using the AngioSeal closure device: experience with 161 interventions in diabetic patients with critical limb ischemia. J Vasc Surg 2008;47:782-8.

72 Treitl KM, König C, Reiser MF, et al. Complications of transbrachial arterial access for peripheral endovascular interventions. J Endovasc Ther 2015:22:63-70.

73 Kiemeneij F, Laarman GJ, Odekerken D, et al. A randomized comparison of percutaneous transluminal coronary angioplasty by the radial, brachial and femoral approaches: the access study. J Am Coll Cardiol 1997;29:1269-75.

74 Calsina Juscafresa L, Llort Pont C, Clará Velasco A. CUSUM analysis of brachial artery access for peripheral endovascular interventions. Int Angiol 2014;33:441-5

75 Roche A, Griffin E, Looby S, et al. Direct carotid puncture for endovascular thrombectomy in acute ischemic stroke. J Neurointerv Surg 2019;11:647-52.

76 Jadhav AP, Ribo M, Grandhi R, et al. Transcervical access in acute ischemic stroke. J Neurointerv Surg 2014;6:652-7.

77 Castaño C, Remollo S, García MR, et al. Mechanical thrombectomy with 'ADAPT' technique by transcervical access in acute ischemic stroke. Neuroradiol J 2015;28:617-22.

78 Yu SCH, Cheng HKM, Wong GKC, et al. Transvenous embolization of dural carotidcavernous fistulae with transfacial catheterization through the superior ophthalmic vein. Neurosurgery 2007;60:1032-7.

79 Orlov K, Gorbatykh A, Berestov V, et al. Superselective transvenous embolization with Onyx and n-BCA for vein of Galen aneurysmal malformations with restricted transarterial access: safety, efficacy, and technical aspects. Child's Nervous System 2017:33:2003-10.

80 Molitch ME. Diagnosis and treatment of pituitary adenomas. JAMA 2017:317:516-24.

81 Lee DJ, Ahmadpour A, Binyamin T, et al. Management and outcome of spontaneous cerebral venous sinus thrombosis in a 5-year consecutive single-institution cohort. $J$ Neurointerv Surg 2017;9:34-8.

82 Klisch J, Huppertz HJ, Spetzger U, et al. Transvenous treatment of carotid cavernous and dural arteriovenous fistulae: results for 31 patients and review of the literature. Neurosurgery 2003;53:836-57.

83 Hui FK, Abruzzo T, Ansari SA. Endovascular interventions for idiopathic intracranial hypertension and venous tinnitus. Neuroimaging Clin N Am 2016;26:289-99.

84 Houdart E, Saint-maurice J-P, Chapot R, et al. Transcranial approach for venous embolization of dural arteriovenous fistulas. J Neurosurg 2002;97:280-6.
85 Gemmete JJ, Chaudhary N, Pandey A, et al. Treatment of carotid cavernous fistulas. Curr Treat Options Neurol 2010;12:43-53.

86 Gandhi CD, Meyer SA, Patel AB, et al. Neurologic complications of inferior petrosal sinus sampling. AJNR Am J Neuroradio/ 2008:29:760-5.

87 Berenstein A, Masters LT, Nelson PK, et al. Transumbilical catheterization of cerebral arteries. Neurosurgery 1997:41:846-50.

88 Harrigan MR, Deveikis JP. Handbook of cerebrovascular disease and neurointerventional technique. Totowa, NJ: Humana Press, Imprint, 2013.

89 Deipolyi A, Bailin A, Hirsch JA, et al. Bilateral inferior petrosal sinus sampling: experience in 327 patients. J Neurointerv Surg 2017;9:196-9.

90 Wolfe SQ, Cumberbatch NMA, Aziz-Sultan MA, et al. Operative approach via the superior ophthalmic vein for the endovascular treatment of carotid cavernous fistulas that fail traditional endovascular access. Neurosurgery 2010;66:293-9.

91 Wenderoth J. Novel approaches to access and treatment of cavernous sinus dural arteriovenous fistula (CS-DAVF): case series and review of the literature. $J$ Neurointerv Surg 2017;9:290-6.

92 Chen C-J, Mastorakos P Caruso JP, et al. Transorbital approach for endovascular occlusion of carotid-cavernous fistulas: technical note and review of the literature. Cureus 2017:9:e976.

93 Taylor LM, Troutman R, Feliciano P, et al. Late complications after femoral artery catheterization in children less than five years of age. J Vasc Surg 1990;11:297-306.

94 Glatz AC, Shah SS, McCarthy AL, et al. Prevalence of and risk factors for acute occlusive arterial injury following pediatric cardiac catheterization: a large singlecenter cohort study. Catheter Cardiovasc Interv 2013;82:454-62.

95 Franken EA, Girod D, Sequeira FW, et al. Femoral artery spasm in children: catheter size is the principal cause. Am J Roentgenol 1982:138:295-8.

96 Flanigan DP, Keifer TJ, Schuler JJ, et al. Experience with iatrogenic pediatric vascular injuries. incidence, etiology, management, and results. Ann Surg 1983:198:430-42.

97 Alexander J, Yohannan T, Abutineh I, et al. Ultrasound-guided femoral arterial access in pediatric cardiac catheterizations: a prospective evaluation of the prevalence, risk factors, and mechanism for acute loss of arterial pulse. Cathet Cardiovasc Intervent 2016;88:1098-107.

98 Kim DW, Raviele AA, Vincent RN. Use of a 3 French system for balloon aortic valvuloplasty in infants. Catheter Cardiovasc Interv 2005;66:254-7.

99 Gross BA, Orbach DB. Addressing challenges in $4 \mathrm{~F}$ and $5 \mathrm{~F}$ arterial access for neurointerventional procedures in infants and young children. $J$ Neurointerv Surg 2014;6:308-13.

100 Ligon RA, Kim DW, Vincent RN, et al. Angiographic follow-up of infants and children undergoing percutaneous carotid artery interventions. Catheter Cardiovasc Interv 2018;91:1301-6.

101 Burrows PF, Robertson RL, Barnes PD. Angiography and the evaluation of cerebrovascular disease in childhood. Neuroimaging Clin N Am 1996;6:561-88.

102 Mansfield PB, Gazzaniga AB, Litwin SB. Management of arterial injuries related to cardiac catheterization in children and young adults. Circulation 1970:42:501-7.

103 Sandgren $T$, Sonesson B, Ahlgren $\mathrm{R}$, et al. The diameter of the common femoral artery in healthy human: influence of sex, age, and body size. J Vasc Surg 1999:29:503-10.

104 He L, Ladner TR, Pruthi S, et al. Rule of 5: angiographic diameters of cervicocerebral arteries in children and compatibility with adult neurointerventional devices. $J$ Neurointerv Surg 2016;8:1067-71.

105 Sahn DJ, Goldberg SJ, Allen HD, et al. A new technique for noninvasive evaluation of femoral arterial and venous anatomy before and after percutaneous cardiac catheterization in children and infants. Am J Cardiol 1982;49:349-55.

106 Shokuhfar T, Hurley MC, Al-Smadi A, et al. MynxGrip vascular closure device use in pediatric neurointerventional procedures. J Neurosurg Pediatr 2018;21:466-70.

107 Prabhu SJ, Padia SA, Valji K, et al. Arterial closure device to achieve hemostasis in children following percutaneous femoral arterial puncture. Pediatr Radiol 2013:43:703-8

108 Wessel DL, Keane JF, Fellows KE, et al. Fibrinolytic therapy for femoral arterial thrombosis after cardiac catheterization in infants and children. Am J Cardiol 1986;58:347-51

109 Peuster M, Bertram H, Fink C, et al. Percutaneous transluminal angioplasty for the treatment of complete arterial occlusion after retrograde cardiac catheterization in infancy. Am J Cardiol 1999;84:1124-6.

110 Lin PH, Dodson TF, Bush RL, et al. Surgical intervention for complications caused by femoral artery catheterization in pediatric patients. J Vasc Surg 2001;34:1071-8.

111 Kothari SS, Kumar RK, Varma S, et al. Thrombolytic therapy in infants for femoral artery thrombosis following cardiac catheterisation. Indian Heart J 1996;48:246-8

112 Gupta AA, Leaker M, Andrew M, et al. Safety and outcomes of thrombolysis with tissue plasminogen activator for treatment of intravascular thrombosis in children. $J$ Pediatr 2001;139:682-8.

113 Aspalter M, Domenig CM, Haumer M, et al. Management of iatrogenic common femoral artery injuries in pediatric patients using primary vein patch angioplasty. J Pediatr Surg 2007;42:1898-902.

114 Sadat U, Hayes PD, Varty K. Acute limb ischemia in pediatric population secondary to peripheral vascular cannulation: literature review and recommendations. Vasc Endovascular Surg 2015;49:142-7. 